\title{
VULNERABILIDADE SOCIAL, DESAFIOS EPISTÊMICOS E CONHECIMENTOS RIVAIS: POR DIÁLOGOS MAIS HORIZONTAIS
}

\author{
SOCIAL VULNERABILITY, EPISTEMIC CHALLENGES \\ AND RIVAL KNOWLEDGES: \\ FOR MORE HORIZONTAL DIALOGUES
}

Djane Antonucci Correa*

\begin{abstract}
Resistir é um ato político de máxima liberdade. Por vezes, ele se torna a única coisa que se pode fazer. E, então, é uma escolha fácil. Outras, é apenas uma entre muitas opções. A opção da resistência, entretanto, é aquela que nos mantém livres. Ainda que fisicamente presos. Nos mantém vivos ainda que sejamos mortos. (Fernando Horta) ${ }^{1}$
\end{abstract}

\section{RESUMO}

O objetivo deste trabalho é discutir a relação intrínseca entre direitos e deveres a partir de estudos recentes acerca do papel social do intelectual crítico, paralelamente a discussões que venho desenvolvendo em torno do papel social da universidade mediante a constituição do conhecimento hegemônico e a emergência de outras possibilidades epistemológicas (CORREA, 2017a). O terceiro ponto de discussão e conexão com os demais são as políticas de decolonialidade em detrimento do ato de descolonizar (RODRÍGUEZ, 2017) de maneira que emerjam questões que levem a reflexões sobre ser um pensador politizado e, por conseguinte, politizar afazeres na perspectiva pragmática. Por fim, para pensar sobre direitos humanos, trago para análise um dos trabalhos que coordeno no "Laboratório de Estudos do Texto" da Universidade estadual de Ponta Grossa, UEPG, uma proposta de trabalho homônima que tem como participantes adolescentes em cumprimento de medida socioeducativa. Considerando a complexidade das relações sociais e seus sistemas de desigualdade e exclusão, concluo o texto enfatizando a necessidade de diálogos horizontais com outras epistemologias, saberes não legitimados, experiências sociais que também produzem conhecimentos e constroem referências para diferentes atores sociais.

Palavras-chave: Direitos e deveres; desentendimento; possibilidades epistemológicas.

\footnotetext{
* Universidade Estadual de Ponta Grossa (UEPG), Ponta Grossa, Paraná, Brasil. djaneantonucci@gmail.com

1 HORTA, F. (2018). O que é resistir? O que é resistência? Disponível em: https://jornalggn.com.br/blog/ fernando-horta/o-que-e-resistir-o-que-e-resistencia-por-fernando-horta. Acesso em: 21 mai. 2018, 10:45:30.
} 


\section{ABSTRACT}

This work aims at discussing the intrinsic relation between rights and duties from the standpoint of recent studies on the critical intellectual's social role, and at the same time putting forward some discussions that I have been developing around the social role of the university regarding the constitution of hegemonic knowledge and the emergence of other epistemological possibilities (CORREA, 2017a). A third point of discussion connected to the themes above, refers to decolonization policies to the detriment of the act of decolonizing in order to arise issues that might lead to reflections upon being a politicized thinker and, consequently, politicize doings in the pragmatic perspective. Finally, to propose a reflection upon human rights, I resort to an analysis of the projects coordinated at the "Laboratory of Text Studies" (LET) at the State University of Ponta Grossa (UEPG), a work proposal named after the laboratory whose participants are juvenile offenders in socio-educational measure. Taking into consideration the complexity of social relations and their inequality and exclusion systems, I finish the text emphasizing the necessity to create horizontal dialogues with other epistemologies, non-legitimate knowledges and social experiences that also produce knowledges and built references to different social actors.

Keywords: Rights and duties. Struggles. Epistemological possibilities.

\section{CONSIDERAÇÕES INTRODUTÓRIAS}

No ano em que a Declaração Universal dos Diretos Humanos completa 70 anos, para iniciar este trabalho, retomo os preceitos nela contidos, de igualdade e liberdade aos seres humanos, independentemente da raça, cor, sexo, idioma, religião, opinião política ou de outra natureza, origem nacional ou social, riqueza, nascimento, território a que pertence ou qualquer outra condição.

Em vigor desde 10 de dezembro de 1948, o documento traz no Artigo XXVIII a seguinte regra de conduta: "Todo ser humano tem direito a uma ordem social e internacional em que os direitos e liberdades estabelecidos na presente Declaração possam ser plenamente realizados". (DECLARAÇÃO UNIVERSAL DOS DIREITOS HUMANOS, p. 15).

E prossegue no Artigo XXIX:

1. Todo ser humano tem deveres para com a comunidade, na qual o livre e pleno desenvolvimento de sua personalidade é possível.

2. No exercício de seus direitos e liberdades, todo ser humano estará sujeito apenas às limitações determinadas pela lei, exclusivamente com o fim de assegurar o devido reconhecimento e respeito dos direitos e liberdades de outrem e de satisfazer as justas exigências da moral, da ordem pública e do bem-estar de uma sociedade democrática (DECLARAÇÃO UNIVERSAL DOS DIREITOS HUMANOS, p. 15-16). 
Com base nos dois artigos supramencionados, vou realçar o direito a uma ordem social e internacional em que os direitos e liberdades possam ser plenamente realizados associados aos deveres para com a comunidade. Assim sendo, os efeitos da dicotomização entre direitos e deveres é o primeiro ponto de discussão deste artigo.

Para trazer essa problematização dicotômica do ponto de vista acadêmico, em um segundo momento, trago algumas considerações de estudos recentes acerca do papel social do intelectual crítico e discussões atuais que venho desenvolvendo em torno do papel social da universidade mediante a construção do conhecimento hegemônico em detrimento de saberes subalternos e a emergência de outras possibilidades epistemológicas² ${ }^{2}$ (CORREA, 2017a). Para tanto, é necessário primeiramente repensar o que temos chamado de "crítico", com o objetivo de fazer um exame ou uma reflexão com base em critérios distintos para enfatizar o uso recorrente do termo, não só fazendo referência ao intelectual crítico, como também ao leitor crítico e à atitude ou ao fazer político e crítico em sentido amplo.

O terceiro ponto de discussão e conexão com os demais são as políticas de decolonialidade em detrimento do ato de descolonizar de maneira que emerjam questões que levem à reflexão sobre ser um pensador politizado e, por conseguinte, politizar afazeres na perspectiva pragmática.

Por fim, para pensar sobre direitos humanos, trago para análise um dos trabalhos desenvolvidos dentro do Laboratório de Estudos do Texto (CORREA, 2015, 2017b, 2018; CORREA, FRAGA, 2013), uma proposta de trabalho homônima que tem como participantes adolescentes em cumprimento de medida socioeducativa.

\section{MUNDO CONTEMPORÂNEO, RELAÇÕES SOCIAIS E DESENTENDIMENTO}

Próximo de completarmos duas décadas dentro do terceiro milêmio, o país vive uma intensa crise econômica e política que desenha um momento sóciohistórico de grande conflito e polarização. Vivemos um estado de incertezas, em que interesses e pontos de vista se confrontam, de maneira que todas/os se obrigam a olhar para este panorama inseguro, conflitante e preocupante.

Fabrício (2006) descreve com muita propriedade o conjunto das nossas condições no mundo contemporâneo, quando, por sua vez, a pesquisadora retoma

2. Este artigo faz parte dos estudos desenvolvidos em estágio pós-doutoral (PNPD/CAPES) junto ao Programa de Pós-Graduação em Linguística Aplicada (PosLa) do Centro de Humanidades da Universidade Estadual do Ceará (UECE). 
a contextualização elaborada pelo historiador e teórico de arte Arnold Hauser ([1965] 1976).

Um mundo em crise, que vê abalada a crença no dogma, na lógica formal e no predomínio da razão na filosofia, na ciência, na moral e na arte. Uma época de mudança geral de perspectivas e de inovações sociais, econômicas e tecnológicas, época na qual convivem ideias paradoxais: racionalismo e irracionalismo, cientificismo e misticismo, humanismo e barbárie, intelectualismo e antintelectualismo. Panorama responsável pela perda de referências explícitas e gerador de indivíduos em choque, em conflito e desorientados, devido ao colapso de seu sistema de crenças e valores. Mundo contemporâneo? (FABRÍCIO, 2006, p. 45).

Instiga observar que a pesquisadora faz referência ao historiador para mostrar a trajetória análoga contextualizada no século XVI. Nesse panorama, que não é novo, como podemos constatar, mas que nem por isso se torna menos desafiador, a busca por um quadro de referências consistente, coerente e aderente às atuais demandas e interesses individuais e coletivos desafia a todas/os. Nesse sentido, vale lembrar que, como construção, podemos recorrer a outra metáfora, a da "tarefa" (BAUMAN, 2005; CORREA, 2014, 2017a). A busca por um quadro de referências é constante, essas referências precisam ser constantemente revisitadas e o quadro revisto, reformulado ou complementado. Trata-se de uma tarefa complexa para ser executada, que exige compreensão dos fatos e, principalmente, discernimento para separar fatos e informações relevantes de "fake news" para que os conflitos não se expandam de forma descontrolada e sejam contraproducentes.

No que concerne às ideias paradoxais mencionadas por Fabrício (2006), os diferentes modos de pensar e agir de diferentes atores sociais constroem um contexto de alinhavo bem suscetível e de difícil compreensão.

Para pensar sobre esse contexto permeado de conflitos de ideias, o termo "desentendimento" (RANCIÈRE, 1996) auxilia nessa discussão. Trata-se de um tipo determinado de situação da palavra: aquela em que um dos interlocutores, ao mesmo tempo, entende e não entende o que diz o outro.

O desentendimento não é o conflito entre aquele que diz branco e aquele que diz preto. É o conflito entre aquele que diz branco mas não entende a mesma coisa, ou não entende de modo nenhum que o outro diz a mesma coisa com o nome de brancura. (RANCIÈRE, 1996, p. 11).

O filósofo francês observa que não se trata de desconhecimento, uma vez que este pressupõe que um dos interlocutores ou os dois - pelo efeito de uma simples ignorância, de uma dissimulação concertada ou de uma ilusão constitutiva - não sabem o que um diz ou o que diz o outro. Não é tampouco mal-entendido produzido pela imprecisão das palavras. Ambos os argumentos requerem, segundo Rancière (1996), duas medicinas de linguagem que consistem em ensinar o que 
quer dizer falar e "os casos de desentendimento são aqueles em que a disputa sobre o que quer dizer falar constitui a própria racionalidade da situação da palavra". Os interlocutores então entendem e não entendem a mesma coisa nas mesmas palavras" (RANCIÈRE, 1996, p.12).

O desentendimento não diz respeito apenas às palavras. Incide geralmente sobre a própria situação dos que falam. (...) Não diz respeito à questão da heterogeneidade dos regimes de frases e da presença ou ausência de uma regra para julgar gêneros discursivos heterogêneos. Diz respeito menos à argumentação que ao argumentável, à presença ou ausência de um objeto comum entre um X e um Y. Diz respeito à apresentação sensível desse comum, à propria qualidade dos interlocutores ao apresentá-lo. A situação extrema do desentendimento é aquela em que $X$ não vê o objeto comum que $Y$ lhe apresenta porque não entende que os sons emitidos por Y compõem palavras e agenciamentos de palavras semelhantes aos seus (...) essa situação extrema diz respeito, essencialmente, à política. (...) o desentendimento se refere ao que é ser um ser que se serve da palavra para discutir. As estruturas de desentendimento são aquelas em que a discussão de um argumento remete ao litígio acerca do objeto da discussão e sobre a condição daqueles que o constituem como objeto. (RANCIÈRE, 1996, p. 13).

Ao retomar os clássicos da filosofia grega, o filósofo lembra que o que eles nos ensinam é antes de mais nada que "a política não se ocupa do vínculo entre os indivíduos, nem das relações entre os indivíduos e a comunidade, ela é da alçada de uma contagem das 'partes' da comunidade, contagem que é sempre uma falsa contagem, uma dupla contagem ou um erro na contagem". (RANCIÈRE, 1996, p. 21-22). Essas "partes" "títulos da comunidade", retomadas de Aristóteles por Rancière, são divididas em três: a riqueza de poucos, a virtude ou a excelência que dá seu nome aos melhores e a liberdade que pertence ao povo.

Rancière (1996) denomina política à interrupção dos simples efeitos da dominação dos ricos, contáveis, que faz os pobres, incontáveis, existirem enquanto entidade. A política, segundo este filósofo, é assunto de sujeitos, ou melhor, de modos de subjetivação. Por subjetivação vamos entender a produção, por uma série de atos, de uma instância e de uma capacidade de enunciação que não eram identificáveis num campo de experiência dado, cuja identificação, portanto, caminha a par com a reconfiguração do campo da experiência. Ela é um nos sumus, nos existimus. Nesse sentido, subjetividade é a contagem dos incontados. Ultrapassa as relações de poder e alcança as relações de mundo. Subjetivar, desta feita, diz respeito à consciência crítica perceptível por meio do conhecimento, da ciência da capacidade de tomar as rédeas do seu próprio ser.

Por seu turno, a complexidade das relações sociais e dos sistemas de desigualdade e exclusão é descrita por Souza Santos (2006) a partir do ângulo hierárquico. Os sistemas de desigualdade e exclusão são combinações complexas, modelos ideais, uma vez que, na prática, os grupos sociais inserem-se nos dois 
sistemas de pertença hierarquizada. A desigualdade implica um sistema hierárquico de integração social. Quem está embaixo está dentro e sua presença é indispensável. Ao contrário, a exclusão assenta num sistema igualmente hierárquico, mas dominado pelo princípio de segregação: pertence-se pela forma como se é excluído. Quem está embaixo está fora (SOUZA SANTOS, 2006).

Ainda sobre hierarquia nas relações sociais e humanas, na mesma direção do complexo sistema hierárquico de integração social, Bauman (2005) analisa a condição das pessoas a quem não é dado o direito de ter ou de construir uma identidade, as quais são chamadas por ele de subclasse.

\begin{abstract}
Mas mesmo as pessoas a quem se negou o direito de adotar a identidade de sua escolha (situação universalmente abominada e temida) ainda não pousaram nas regiões inferiores da hierarquia do poder. Há um espaço ainda mais abjeto - um espaço abaixo do fundo. Nele caem (ou melhor, são empurradas) as pessoas que têm negado o direito de reivindicar uma identidade distinta da classificação atribuída e imposta. Pessoas cuja súplica não será aceita e cujos protestos não serão ouvidos, ainda que pleiteiem a anulação do veredicto. São as pessoas recentemente denominadas de "subclasse": exiladas nas profundezas além dos limites da sociedade - fora daquele conjunto no interior do qual as identidades (e assim também o direito a um lugar legítimo na totalidade) podem ser reivindicadas e, uma vez reivindicadas, supostamente respeitadas. (BAUMAN, 2005, p. 45).
\end{abstract}

Segundo o filósolo e sociólogo polonês, aos destinados à subclasse (porque abandonou a escola, é mãe solteira vivendo da previdência social, viciado ou ex-viciado em drogas, sem-teto, mendigo ou membro de outras categorias arbitrariamente excluídas da lista oficial dos que são considerados adequados e admisíveis) qualquer outra identidade que possam ambicionar ou lutar para obter é negada a priori. O significado de "identidade da subclasse" é a ausência de identidade, a abolição ou a negação da individualidade, do "rosto" - esse objeto do dever ético e da preocupação moral. Você é excluído do espaço social em que as identidades são buscadas, escolhidas, construídas, avaliadas, confirmadas ou refutadas (BAUMAN, 2005).

\title{
2. CONHECIMENTO VÁLIDO E CONHECIMENTOS RIVAIS
}

Na introdução do livro "Epistemologias do Sul" (2010), Boaventura de Souza Santos e Maria Paula Meneses fazem uma importante conexão entre produção de conhecimentos como reflexo de experiências sociais ao dizer que toda experiência social produz conhecimento e, ao fazê-lo, pressupõe uma ou várias epistemologias. Por essa via, descrevem os modos de atuação das diferentes práticas e atores sociais, 
do que é considerado como conhecimento válido e das tensões e contradições que envolvem as diferentes epistemologias.

Epistemologia é toda a noção ou ideia, refletida ou não, sobre as condições do que conta como conhecimento válido. É por via do conhecimento válido, que uma dada experiência social se torna intencional e inteligível. Não há, pois, conhecimento sem práticas e atores sociais. E como umas e outros não existem senão no interior de relações sociais, diferentes tipos de relações sociais podem dar origem a diferentes epistemologias. As diferenças podem ser mínimas e, mesmo se grandes, podem não ser objeto de discussão, mas, em qualquer caso, estão muitas vezes na origem das tensões e contradições presentes nas experiências sociais sobretudo quando, como é normalmente o caso, estas são constituídas por diferentes tipos de relações sociais. (SOUZA SANTOS; MENESES, 2010, p.9).

Os autores do texto introdutório, que são também organizadores da obra, ainda lembram que, em sentido mais amplo, as relações sociais são sempre culturais, intra-culturais ou inter-culturais, e são também políticas, representam distribuições desiguais de poder. Assim sendo, qualquer conhecimento válido é sempre contextual, tanto em termos de diferença cultural como em termos de diferença política. Para além de certos patamares de diferença cultural e política, as experiências sociais são constituídas por vários conhecimentos, cada um com seus critérios de validade, ou seja, são constituídas por conhecimentos rivais.

Nesse sentido, é importante trazer Mignolo, como já fiz em Correa (2017b), para lembrar que, até o meio do século XX, a diferença colonial respeitava a distinção clássica entre centros e periferias. Na segunda metade do século, a emergência do colonialismo global, gerenciado pelas corporações transnacionais, apagou a distinção que era válida para as formas iniciais de colonialismo e colonialidade do poder. No passado, a diferença colonial situava-se lá fora, distante do centro. Hoje emerge em toda parte, na periferia dos centros e nos centros da periferia (MIGNOLO, 2003).

A diferença colonial é o espaço onde emerge a colonialidade do poder. A diferença colonial é o espaço onde as histórias locais que estão inventando e implementando os projetos globais encontram aquelas histórias locais que os recebem; é o espaço onde os projetos globais são forçados a adaptar-se, integrar-se ou onde são adotados, rejeitados ou ignorados. A diferença local é, finalmente, o local ao mesmo tempo físico e imaginário onde atua a colonialidade do poder, no confronto de duas espécies de histórias locais visíveis em diferentes espaços e tempos do planeta. Se a cosmologia ocidental é um ponto de referência historicamente inevitável, as múltiplas confrontações de dois tipos de histórias locais desafiam dicotomias. (MIGNOLO, 2003, p. 10).

Voltando a Souza Santos e Meneses (2010), a pluralidade epistemológica do mundo e, com ela, o reconhecimento de conhecimentos rivais dotados de critérios diferentes de validade tornam visíveis e credíveis espectros muito mais amplos de ações e de agentes sociais. Tal pluralidade não implica o relativismo epistemológico 
ou cultural, mas certamente obriga a análises e avaliações mais complexas dos diferentes tipos de interpretações e de intervenções no mundo produzidos pelos diferentes tipos de conhecimento. O reconhecimento da diversidade epistemológica tem hoje lugar, tanto no interior da ciência (a pluralidade interna da ciência), como na relação entre ciência e outros conhecimentos (a pluralidade externa da ciência).

Ao designar a diversidade epistemológica do mundo por epistemologias do Sul, os autores concebem "o Sul" como uma relação extremamente desigual, metaforicamente como um campo de desafios epistêmicos, que procuram reparar os danos e impactos historicamente causados pelo capitalismo na sua relação colonial com o mundo. A ideia central é que o colonialismo, para além de todas as dominações por que é conhecido, foi também uma dominação epistemológica, uma relação extremamente desigual de saber-poder que conduziu à supressão de muitas formas de saber próprias dos povos e/ou nações colonizados. As epistemologias do Sul são o conjunto de intervenções epistemológicas que denunciam essa supressão epistemológica, valorizam os saberes que resistiram com êxito e investigam as condições de um diálogo horizontal entre conhecimentos.

A partir dessa lacuna epistemológica, os mesmos autores (2010) interrogam sobre o porquê da dominação, nos dois últimos séculos, de uma epistemologia que eliminou da reflexão epistemológica o contexto cultural e político da produção e reprodução do conhecimento; sobre as consequências de uma descontextualização e sobre a possibilidade de haver epistemologias alternativas.

Em estudo sobre o tema, Nogueira de Alencar e Martins Ferreira (2016) reafirmam essa ausência de diálogo mais horizontal, e de epistemologias alternativas ao dizerem que a colonialidade do poder se manifesta constituindo espaços epistemológicos hegemônicos, enquanto a colonialidade do saber determina o monopólio do conhecimento, a predominância do saber pelos ditames do eurocentrismo.

Por outro lado, Clelia O. Rodríguez $z^{3}$ faz um chamado crítico indispensável para os estudos acadêmicos contemporâneos ao distinguir as políticas de decolonialidade do ato de descolonizar, ressaltando que a maneira como as expressões "decolonizar

3. RODRÍGUEZ, C. O. (2017). Como a Academia se vale da pobreza, da opressão e da dor para sua masturbação intelectual. Disponível em: https://www.geledes.org.br/como-academia-se-vale-dapobreza-da-opressao-e-da-dor-para-sua-masturbacao-intelectual/. Acesso em: 01 mar. 2018, 18:15:30.

Originalmente publicado em RaceBaitR como "How Academia Uses Poverty, Oppression, and Pain for Intellectual Masturbation". Tradução coletiva de Bruna Paz, Helena Rosa, Marcos Queiroz, Mariana Barbosa, Roberta Borges e Uila Gabriela Cardoso. 
a mente/coração" ou simplesmente o verbo "decolonizar" têm sido utilizados em espaços acadêmicos é preocupante.

Estou preocupada sobre como o termo está começando a evocar uma pretensão de livrar-se de práticas coloniais, sob o comando daqueles entes que, em realidade, operam totalmente submetidos a essas práticas. A decolonialidade soa e significa coisas diferentes para mim, enquanto mulher de cor, do que deve significar para uma pessoa branca. E por que isso importa? Por que eu sinto um incômodo quando eu ouço este termo em espaços acadêmicos, majoritariamente brancos, onde pessoas de cor (1) permanecem como tokens (2)? Por que minha garganta se torna uma prisão de palavras que não podem ser articuladas em frases completas? É possível que seja porque nessas práticas pretensamente "decolonizantes" estamos sendo colonizados mais uma vez. (RODRIGUEZ, 2017, online).

Ao fazer um relato ligado à pretensão acadêmica de "dar voz" (grifos meus), Rodríguez (2017) diz não ter o privilégio de ser tratada com a mesma humanidade com que um erudito branco ou alguém que age como tal é tratado. A atuação daqueles que nos "concedem" (grifos da autora) humanidade e que afirmam estar criando espaços para pessoas de cor precisa ser desafiada. Eles promovem ações afirmativas de formas risíveis.

Espaços acadêmicos não são precisamente seguros, nem mesmo são locais onde a liberdade de expressão é realmente bem-vinda. Nem todos temos o luxo de falar livremente sem sermos penalizados e chamados de radicais, emocionais demais, raivosos ou não acadêmicos. Na verdade, o trabalho de decolonização abre mão daquelas pessoas sobre as quais se referem. Afirmar que estamos no campo dos estudos de decolonialidade não é o suficiente. Não é surpresa que mesmo aqueles que estão engajados em decolonizar os métodos reproduzam e sofisticam os métodos eurocêntricos, porque estamos envolvidos no colonialismo neste ambiente disseminado por corporações. (RODRÍGUEZ, 2017, online).

$\mathrm{Na}$ linha dos questionamentos acerca do papel acadêmico, a educadora que pesquisa direitos humanos e ética e também tem interesse por perspectivas decoloniais para ensino e metodologias críticas incita-nos a pensar como pensadores politizados, e, como tal, refletir sobre essas experiências se estivermos realmente envolvidos em discussões profundas sobre solidariedade, resistência e territórios nas ciências humanas. Em acréscimo, Rodríguez (2017) propõe pensar sobre como nós, enquanto acadêmicos, estamos nos empenhando no trabalho de alcançar os cânones e, ao fazê-lo, podemos realmente admitir o que nos levou até lá? Muitos de nós, operando em espaços acadêmicos homogêneos (com alguns toques de tendência liberal), conformam-se quando essa pergunta é feita sem rodeios. 


\section{O INTELECTUAL CRÍTICO, UMA ABORDAGEM PRAGMÁTICA E UMA EXPERIÊNCIA DE TRABALHO: PRODUÇÃO DE CONHECIMENTO?}

Ao dar sequência à discussão acerca da reprodução de métodos hegemônicos de trabalho e dos agenciamentos acadêmicos, é preciso repensar também as abordagens críticas. Postura crítica, para Rajagopalan (2017), está longe de pressupor essa ou aquela visão teórica, esse ou aquele posicionamento ideológico, o pensamento crítico valoriza o livre exercício de pensar, não importando o destino de tais indagações, muito menos ideias formadas de antemão sobre ela.

O que move o pensamento crítico é, com bem aponta Horkheimer, uma proposição de ordem existencial que nos lembra que o estado das coisas constatado no mundo que nos cerca não precisava estar daquele mesmo jeito, pois não é mais daquela forma como se apresenta, pois houve manipulações maquiavélicas de partes interessadas no passado e, por conseguinte, é passível de ser modificado, bastando apenas vontade e garra para fazê-lo. (RAJAGOPALAN, 2017, p. 14).

Quando se fala em abordagem crítica, estamos nos referindo a uma atitude diante da própria atividade de conduzir nossas pesquisas, uma atitude no que diz respeito à questão de direcionar nosso olhar para o mundo e, acima de tudo, a um desejo de fazer com que nossa postura enquanto acadêmicos tenha algum impacto palpável sobre nosso objeto de pesquisa. Nesse sentido, a abordagem crítica coloca em cheque a longa tradição de fazer pesquisa que se vangloria do distanciamento proposital de seu objeto de pesquisa, movida por uma determinação ferrenha de não "deturpar" a ordem das coisas observadas, resistindo a qualquer impulso que leve o pesquisador a sair da sua toca e a intervir na realidade que ele constata (RAJAGOPALAN, 2017).

Para o pesquisador, postura crítica não é subproduto ou simples desdobramento de uma metodologia específica. Também não há técnicas de pesquisa que automaticamente caracterizem o pesquisador como alguém crítico ou que o ajudem a se transformar em um. Ou seja, o trabalho crítico não é algo que nasce de um procedimento que automaticamente resulta nos fins desejados. Para ser crítico, o pesquisador precisa ter certa desconfiança em relação a todas as conclusões a que ele chega, especialmente quando o caminho trilhado parece oferecer conclusões simples e certeiras. E isso inclui suas próprias certezas, fruto de sedimentação do seu próprio pensamento e das conclusões nele baseadas

Por seu turno, conforme já trazido em Correa (2017a, 2017b), a resposta de Jacob Mey à entrevista de Silva (2014) continua basilar para compor a discussão proposta neste momento. 
Penso que todos os intelectuais adquirem alguma dose de pragmática em suas reflexões. E isso porque se um intelectual não é crítico, ele não é um intelectual. Um intelectual que apenas se subscreve às teorias correntes e às vertentes hegemônicas é uma pessoa que basicamente abdica de seu direito de ser intelectual. Um intelectual é crítico por definição. (SILVA, 2014, p.177).

Nessa tarefa contínua de fazer pesquisas a partir dos conflitos acerca do modo de olhar para o mundo, em 2007, juntamente com uma equipe de trabalho que compartilha os mesmos interesses, criamos o Programa de extensão Laboratório de Estudos do Texto (CORREA, 2015, 2017a, 2017b, 2018; CORREA, FRAGA, 2009, 2010a, 2010b, 2013). Desde então coordeno e desenvolvo atividades com produções escritas junto a adolescentes em cumprimento de medida socioeducativa em regime fechado no Centro de Socioeducação de Ponta Grossa - Paraná e, mais recentemente, em 2017, na FASEPA (Fundação de atendimento socioeducativo do estado do Pará).

Nesta proposta, venho atrelando trabalhos em campo em unidades socioeducativas $^{4}$, como já dito, e escolas públicas. Os projetos abrangem os eixos da pesquisa, do ensino e da extensão, mantendo o foco dos estudos sobre o tema "Linguagem e exclusão" por meio de um Programa de extensão homônimo, "Laboratório de Estudos do Texto" (LET) ${ }^{5}$, conforme já dito. Os participantes são, além dos adolescentes em cumprimento de medida socioeducativa, acadêmicas e acadêmicos dos Cursos de Licenciatura em Letras da UEPG e também do Mestrado em Estudos da Linguagem, além de estudantes da educação básica de escolas públicas e equipes de trabalho de unidades socioeducativas, tais como assistentes sociais, pedagogas, educadores sociais, diretoras e diretores de unidade, entre outros. Por meio da utilização de gêneros textuais verbais e nãoverbais, basicamente narrativas de experiências pessoais, textos jornalísticos e pinturas de telas, a equipe organizou seis livros ${ }^{6}$, editou uma revista, um jornal

4. Para além de Ponta Grossa, outras unidades socioeducativas do Paraná também participaram do trabalho. As atividades foram compartilhadas ainda com todas as escolas estaduais do estado do Paraná e com Centros de socioeducação e escolas públicas dos Estados de Goiás, Mato Grosso do Sul, Minas Gerais, Rio de Janeiro, Ceará, Piauí e Pará.

5. Laboratório de Estudos do Texto da Universidade Estadual de Ponta Grossa (LET - UEPG). Apoio: MEC - PROEXT/UEPG 2009 - Convênio n.012/2010

MEC/PROEXT - Convênio UEPG/MEC - N. 05/2013- SICONV N. 782423/2013.

6. Embora eu tenha participado de todas as frentes de trabalho como coordenadora geral do Programa de extensão, restringirei a minha discussão aos trabalhos que coordenei diretamente, a produção dos livros e do documentário. O trabalho com os jornais foi coordenado pela professora Letícia Fraga e a pintura e exposição de telas pelo professor Álvaro Franco da Fonsega Junior. 
da unidade e organizou uma exposição das telas produzidas pelos internos, e produziu um documentário. ${ }^{7}$

A concepção deste laboratório vislumbrou, desde o início, ser uma ampliação do espaço de discussão acerca do papel das universidades públicas e da constituição do sujeito acadêmico. O desafio proposto à coordenação geral do Programa, à coordenação dos projetos específicos e à equipe de execução das propostas vem sendo delinear estratégias que possibilitem ao professor pesquisador refletir sobre a maneira como sua atuação pode ser potencializada em termos de comprometimento social, considerando novas possibilidades metodológicas e epistemológicas.

Assim sendo, inserir nessa reflexão protagonistas advindos de um estrato social marginal vem sendo uma das formas de propor à comunidade acadêmica a troca de saberes e experiências, possibilitando, dessa forma, pensar sobre as mais diversas questões sociais com as/os adolescentes e não para eles. Desse modo, inserimos de maneira mais sistemática graduandos nessas atividades, de modo a fortalecer o vínculo entre extensão, pesquisa e ensino, a contribuir para a flexibilização curricular dos Cursos de Licenciatura em Letras e ampliar os espaços de atuação do professor em formação. Ademais, paulatinamente os acadêmicos do mestrado vêm se envolvendo nessas atividades de maneira que os vínculos entre a extensão, a pesquisa e o ensino vêm se consolidando e se integrando nos três eixos.

No que tange à reflexão sobre privação de liberdade, na epígrafe deste artigo, Fernando Horta (2018) nos diz que resistir é um ato político, gesto maior de liberdade. O direito à liberdade está, como apresentado logo em seguida, entre as palavras-chave na Declaração Universal dos Direitos Humanos. Entretanto, ainda na epígrafe, o próprio conceito de liberdade está na ordem do desentendimento discutido em Rancière, uma vez que relaciona liberdade à resistência, mesmo que fisicamente estejamos presos ou, indo mais além, estejamos mortos. Retomo ainda

7. CORREA, D. A. (2017a). Entre hegemonias, saberes subalternos e possibilidades epistemológicas: discussões iniciais. L\&S Cadernos de Linguagem e Sociedade, v. 18, p. 219-235.

CORREA, D. A. et al. (2015). Composições - revista do LET. Ponta Grossa: UEPG-PROEX.

CORREA, D. A.; FRAGA, L. (org.). (2010a). Ecos. Volume 1. Ponta Grossa: Edições Muitas Vozes. (org.). (2010b). Ecos. Volume 2. Ponta Grossa: Edições Muitas Vozes.

(org.). (2009). Fuga de Vozes. Ponta Grossa: EDUEPG - Editora da Universidade Estadual

de Ponta Grossa.

(org.). (2013). Sentidos à memória. Ponta Grossa: UEPG-PROEX - Muitas Vozes.

CORREA, D. A. (org). (2018). Saberes integrados: sociedade e universidade. 1. Ed. Container Edições, Edições Muitas Vozes.

(2017b). Sobre o protagonismo na linguagem escrita e novos modos de interação. Revista

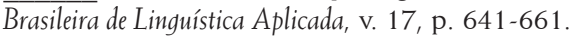

Documentário do LET. direção: Djane Antonucci Correa. Produção e roteiro: Émerson Lima, Taís Regina Güths, Yara Fernanda Novatski. Ponta Grossa,Explorata produtora, 2017. DVD (35min.). Son. Color. 
Rodríguez (2017), que nos encoraja a sermos pensadores politizados, quando refletimos acerca de experiências e discussões profundas sobre solidariedade, resistência e territórios nas ciências humanas.

A trajetória/experiência de trabalho junto a adolescentes em cumprimento de medida socioeducativa em regime fechado mostra que eles não entendem por liberdade a mesma coisa que a maioria das pessoas com as mesmas palavras, conforme Rancière (1996). E aí já despontam as primeiras tensões e contradições manifestadas por saberes não hegemônicos. $\mathrm{Na}$ análise das combinações sociais complexas e hierárquicas apresentada por Souza Santos (2006) e na contagem das partes de que fala Rancière (1996), a maioria deles toma parte, em um primeiro momento, do sistema de desigualdade, uma vez que se integram socialmente por meio da construção de referências que os aloca em uma subclasse específica, conforme descrito por Bauman (2005).

Em um segundo momento, quando cometem um ato infracional e precisam prestar contas sobre ele, eles passam a pertencer pela forma como são excluídos socialmente e, a partir desse ponto, voltar a fazer parte da contagem das partes se torna uma possibilidade distante por razões diversas.

A pobreza, o desemprego e o uso abusivo de álcool e outras drogas dentro das famílias brasileiras aumentam a violência dentro do contexto familiar. Pais usuários e desempregados tornam-se mais violentos e, para fugir disso, os adolescentes passam a ficar nas ruas e, então, há mais um motivo para os grupos se formarem e se envolverem em atos infracionais. Quando esses adolescentes chegam a nossas instituições, denominadas Centros de Socioeducação, trazem com eles todos esses problemas: a dependência química, o abandono familiar, a evasão escolar, a vizinhança violenta e tantos outros sofrimentos. (KANAWATE, 2018, p.105).

Esse contexto do mundo contemporâneo não favorece minimamente a obtenção de referências explícitas que orientem a conduta e permitam discernimento suficiente para determinar os direitos individuais considerando os direitos coletivos, considerando o outrem, e, por conseguinte, os deveres, conforme apresentado no início deste artigo. Os motivos e os olhares são mais uma forma de se delinear o desentendimento, o litígio apresentado por Rancière (1996).

Negligência familiar? Ausência de políticas públicas? Vagabundagem! Falta de corretivo! O Estado passa a mão na cabeça desses adolescentes. Faz tudo e eles não aproveitam nada! Foi uma limpa! O que aconteceu? Qual a história de vida? Basta! Isso é coisa de gente permissiva, de gente "madeira", como se diz na gíria do "sistema". Esse já era! Menos um pra incomodar! O que importa mesmo é que: "Bandido bom é bandido morto". (CARNEIRO E SILVA, 2018, p. 93).

Ao trazer o leque de possibilidades, os diversos olhares e pontos de vista e tentar compreender, dentro do sistema social hierárquico, o nível de complexidade 
que leva a/o adolescente a cometer o ato infracional, a cumprir medida socioeducativa $\mathrm{e}$, às vezes, à morte, evidenciam-se os efeitos da dicotomização entre direitos e deveres principalmente se considerarmos os diversos olhares sobre o mesmo "objeto" (grifos meus).

Essas e outras indagações e afirmações ecoam na sociedade e entre os murmúrios das vozes de profissionais e autoridades do próprio 'sistema' quando se noticia a morte de um adolescente e/ou jovem com passagem pelo sistema socioeducativo. Sim! Infelizmente, não são todos que atuam no 'sistema' que entendem as contradições da realidade e questionam os porquês de uma vida permeada por violências e violações. Ou, se não é por falta de entendimento, é por convicção de quem é preparado para punir e/ou para defender a punição sem se dar ao trabalho de se preocupar com as reais razões que sustentam a violência e ainda de perceber que a violência que mata o outro é a mesma capaz de lhe tirar a própria vida. (CARNEIRO E SILVA, 2018, p. 93).

Retomamos, também, Bauman (2005) neste ponto para reflexão acerca das pessoas que se situam na subclasse, pessoas cuja súplica não será aceita e cujos protestos não serão ouvidos. Ainda que pleiteiem a anulação do veredicto, elas estão exiladas nas profundezas além dos limites da sociedade. São pessoas sem nomes, rostos e individualidade.

Com efeito, os limites entre os direitos e deveres dos humanos são tênues e não são dissociados. Ao contrário, são conjugados e, como tal, fundidos nesse sistema de combinações. Estabelecê-los é um desafio que requer conhecimentos produzidos por diferentes atores sociais e diferentes critérios de validade que horizontalmente tragam à baila os vários conhecimentos rivais.

O que buscamos é que nossos adolescentes não saiam daqui sem, pelo menos, se responsabilizarem pelos atos que cometeram e tenham uma oportunidade na escola e na profissionalização, que se fortifiquem os vínculos afetivos com a família ou que encontremos para eles um lugar onde possam permanecer até se tornarem responsáveis pela própria vida. (KANAWATE, 2018, p.105).

\section{CONSIDERAÇÕES FINAIS}

Existe uma saudação comum entre as/os socioeducandas/os que vim a conhecer desenvolvendo esses trabalhos dentro do universo da socioeducação. Normalmente, eles mandam "um salve" para dar um "olá" a colegas ou a outras pessoas em quem confiam ou por quem cultivam simpatia. Nunca perguntei para eles qual a origem da saudação, mas a ambiguidade dela sempre me inquietou.

Seja para saudar ou para pedir socorro, temos duas circunstâncias que fazem ressoar o modo como Rodríguez (2017) chama atenção para os estudos de decolonialidade em detrimento do ato de descolonizar dentro dos espaços 
acadêmicos. Em dez anos de trabalho junto a essa comunidade vulnerável, olho para o que foi produzido e acho difícil vislumbrar avanços e contribuições consideráveis que não passem pela reprodução de métodos já reconhecidos. Para além dos registros das experiências, das histórias de vida pregressas e das que estão por vir, é preciso cuidado para não estigmatizar ainda mais essas/esses adolescentes, fazendo com que as práticas e métodos colonizadores, uma vez repetidos, sejam reafirmados. Eis o maior desafio.

Nesse sentido, não é papel da universidade pública protagonizar mudanças sociais. Ela não tem função de nem estrutura para ser agente direto dessas mudanças. Não é esse seu papel. O sujeito acadêmico, para não ser somente reprodutor, consagrador e sofisticador de métodos já consagrados, precisa ser efetivamente crítico, ou numa linguagem mais direta, conforme utilizada por Rajagopalan (2017), desconfiado em relação ao que está posto, concluso. Assim, precisa se dispor a dialogar horizontalmente com outras epistemologias, saberes não legitimados, experiências sociais que também produzem conhecimentos.

Ao trocar saberes e experiências, ouvi-las para pensar com quem as vivencia e não para pensar sobre elas ou para quem as vivencia, temos pensadores politizados, que podem trazer os incontáveis à visibilidade por meio de outros olhares, não só para contagem de mortos ou de episódios de violência, mas também para politizar afazeres no sentido de trazer outras possibilidades epistemológicas para registro e diálogo com as epistemologias já consolidadas.

Dessa forma, o pensamento dicotômico, como os direitos e deveres do cidadão, pode ganhar roupagens cujas fronteiras não sejam objetos de limitação e domesticação do pensamento e o desentendimento pode ser produtivo para os seres humanos.

\section{REFERÊNCIAS}

BAUMAN, Z. (2000). Em busca da política. Trad. Marcus Penchel. Rio de Janeiro, Zahar.

BAUMAN, Z. (2005). Identidade: Entrevista a Benedetto Vecchi. Trad. Carlos Alberto Medeiros. São Paulo: Jorge Zahar.

CARNEIRO E SILVA, S. A cadeia tem algo a ensinar? Lições de Socioeducação recebidas na prisão. (2018). In: CORREA, D. A.; NOVATZKI, Y. F.; GÜTHS, T. R. (2018). Viagens de Aprendizagem. Ponta Grossa: Container Edições, Edições Muitas Vozes. p.21-31. 
CORREA, D. A. et al. (2015). Composições - revista do LET. Ponta Grossa: UEPGPROEX.

CORREA, D. A.; FRAGA, L. (org.). (2010a). Ecos. Volume 1. Ponta Grossa: Edições Muitas Vozes.

CORREA, D. A.; FRAGA, L. (org.). (2010b). Ecos. Volume 2. Ponta Grossa: Edições Muitas Vozes.

CORREA, D. A.; FRAGA, L. (org.). (2009). Fuga de Vozes. Ponta Grossa: EDUEPG - Editora da Universidade Estadual de Ponta Grossa.

CORREA, D. A.; FRAGA, L. (org.). (2013). Sentidos à memória. Ponta Grossa: UEPGPROEX - Muitas Vozes.

CORREA, D. A. (2014). Práticas linguísticas e ensino de língua: variáveis políticas. In: CORREA, D. A. (org.). Política linguística e ensino de língua. Campinas: Pontes, v. 1, p. 21-37.

CORREA, D. A. (2017a). Entre hegemonias, saberes subalternos e possibilidades epistemológicas: discussões iniciais. L\&S Cadernos de Linguagem e Sociedade, v. 18, p. 219 235.

CORREA, D. A. (2017b). Sobre o protagonismo na linguagem escrita e novos modos de interação. Revista Brasileira de Linguística Aplicada, v. 17, p. 641-661.

CORREA, D. A. (org). (2018). Saberes integrados: sociedade e universidade. 1. Ed. Container Edições, Edições Muitas Vozes.

CORREA, D. A.; NOVATZKI, Y. F.; GÜTHS, T. R. (2018). Viagens de Aprendizagem. Ponta Grossa: Container Edições, Edições Muitas Vozes. p. 21-31.

DECLARAÇÃO UNIVERSAL DOS DIREITOS HUMANOS. Assembleia Geral das Nações Unidas em Paris. 10 dez. 1948. Disponível em: http://www.onu.org.br/ img/2014/09/DUDH.pdf. Acesso em: 10 abr. 2018, 17:30:30.

Documentário do LET. Direção: Djane Antonucci Correa. Produção e roteiro: Émerson Lima, Taís Regina Güths, Yara Fernanda Novatzki. Ponta Grossa, Explorata produtora, 2017. 1 DVD (35 min.). Son. Color.

FABRÍCIO, B. F. (2006). Linguística Aplicada como espaço de desaprendizagem. In: MOITA LOPES, L. P. Por uma Linguística Aplicada Indisciplinar. São Paulo: Parábola. 
HORTA, F. (2018). O que é resistir? O que é resistência? Disponível em: https://jornalggn.com. br/blog/fernando-horta/o-que-e-resistir-o-que-e-resistencia-por-fernando-horta. Acesso em: 21 mai. 2018, 10:45:30.

KANAWATE, V. L. (2018). Socioeducação: caminhos e desafios. In: CORREA, D. A.; NOVATZKI, Y. F.; GÜTHS, T. R. Viagens de Aprendizagem. Ponta Grossa: Container Edições, Edições Muitas Vozes. p. 58-60.

MIGNOLO, W. D. (2003). Histórias locais/projetos globais - colonialidade, saberes subalternos e pensamento liminar. Trad. Solange Ribeiro de Oliveira. Belo Horizonte: Editora da UFMG.

NOGUEIRA DE ALENCAR, C.; MARTINS FERREIRA, D. M. (2016). Rajagopalan interpretando Austin: descolonialidades na nova pragmática do hemisfério sul. Delta, vol.32, n.3, p. 613-632.

PINTO, J. P. (2007). Conexões teóricas entre performatividade, corpo e identidades. Delta, São Paulo, v. 23, n. 1, p. 1-26.

PINTO, J. P. (2010). Da língua-objeto à práxis linguística: desarticulações e rearticulações contra hegemônicas. Linguagem em Foco, Fortaleza, v. 2, n. 2, p. 69-83.

PINTO, J. P. (2015). De diferenças e hierarquias no quadro Adelaide às análises situadas e críticas na Linguística Aplicada. Delta, São Paulo, v. 31, p. 199-221.

PINTO, J. P. (2014). Hegemonias, contradições e desafios em discursos sobre língua no Brasil. In: CORREA, D. A. (org.). Política linguística e ensino de língua. Campinas: Pontes, p. 59-72.

PINTO, J. P. (2012). Modernidade e diferença colonial nos discursos hegemônicos sobre língua no Brasil. Muitas Vozes, Ponta Grossa, v. 1, p. 171-180.

RAJAGOPALAN, K. (2014). A pesquisa política e socialmente compromissada em pragmática. In: SILVA, D. N.; FERREIRA, D. M. M.; ALENCAR, C. N. (org.). Nova pragmática: modos de fazer. São Paulo: Cortez, p. 101-128.

RAJAGOPALAN, K. (2017). Postura crítica: um olhar para o mundo (prefácio). In: MARTINS FERREIRA, D. M. (org.). Estudos Críticos da Linguagem. 1. ed. Curitiba: Appris, v. 1.

RANCIÈRE, J. (1996). O desentendimento - política e filosofia. Trad. Ângela Leite Lopes. São Paulo: 34 . 
RODRÍGUEZ, C. O. (2017). Como a Academia se vale da pobreza, da opressão e da dor para sua masturbação intelectual. Disponível em: https://www.geledes.org.br/como-academia-sevale-da-pobreza-da-opressao-e-da-dor-para-sua-masturbacao-intelectual/. Acesso em: 01 mar. 2018, 18:15:30.

SILVA, D. N. (2014). Pragmática, sociedade (e a alma), uma entrevista com Jacob Mey. Delta, 30.1, p. 161-179.

SOUZA SANTOS, B. S. (2006). A gramática do tempo: para uma nova cultura política. São Paulo: Cortez.

SOUZA SANTOS, B. S.; MENESES, M. P. (2010). Introdução. In: SOUZA SANTOS. B. S.; MENESES, M. P. (org.). Epistemologias do Sul. 2. Portugal: Ed. CES: conhecimento e instituições, p. 15-27.

WAISELFISH, J. J. (2016). Mapa da violência 2016: homicídios por arma de fogo no Brasil. Disponível em: https://www.mapadaviolencia.org.br/pdf2016/Mapa2016 armas web.pdf. Acesso em: 10 abr. 2018, 19:20:30.

Recebido: 24/06/2018

Aceito: 8/01/2019

Publicado: 29/03/2019 